\title{
Respiration and Quality of Rough Rice under Unsteady Atmospheric Conditions
}

\author{
Hu, Wenzhong
}

Akimoto, Koichi

The Commerce Department, Nagoya Gakuin University

Hamanaka, Daisuke

Laboratory of Postharvest Science, Division of Bioproduction System Science, Department of Bioproduction Environmental cience, Graduate School of Bioresource and Bioenvironmental Sciences, Kyushu University | Laboratory of Postharvest Science, Division of Bioproduction System Science, Department of Bioproduction Environmental cience, Graduate School of Bioresource and Bioenvironmental Sciences, Kyushu University

\section{Sorour, Hussain}

Postdoctoral Fellow of Japan Society for the Promotion of Science, Laboratory of Postharvest Science, Division of Bioproduction System Science, Department of Bioproduction Environmental cience, Graduate School of Bioresource and Bioenvironmental Sciences, Kyushu University

他

https://doi.org/10.5109/4513

出版情報：九州大学大学院農学研究院紀要. 47 (2)，pp.427-435，2003-02-01. Faculty of Agriculture, Kyushu University バージョン :

権利関係 : 


\title{
Respiration and Quality of Rough Rice under Unsteady Atmospheric Conditions
}

\author{
Wenzhong HU', Koichi AKIMOTO*, Daisuke HAMANAKA**, Hussain \\ SOROUR*** and Yoshiaki HORI
}

\author{
Laboratory of Postharvest Science, Division of Bioproduction System Science, \\ Department of Bioproduction Environmental Science, Faculty of Agriculture, \\ Kyushu University,Fukuoka 812-8581, Japan \\ (Received October 31, 2002 and accepted November 7, 2002)
}

\begin{abstract}
The respiration rates of fresh and rehydrated rough rice under unsteady atmospheric conditions were measured by the pouch method, and quality attributes and amino acid content were also examined. Respiration rates of both fresh and rehydrated rough rice were greatly repressed under conditions of increase in $\mathrm{CO}_{2}$ and decrease in $\mathrm{O}_{2}$ concentrations at 20 and $30^{\circ} \mathrm{C}$. But $\mathrm{O}_{2}$ and $\mathrm{CO}_{2}$ concentrations were decreased quicker for rehydrated rough rice due to higher respiration rate during storage period. Respiratory quotient (RQ) was fluctuated around 0.8-1.0 at over 4.4-6.4\% $\mathrm{O}_{2}$ concentration, and anaerobic respiration was occurred at less than this $\mathrm{O}_{2}$ level. For evaluation of quality, statistical analysis of test of significance showed that there were no significant differences in palatability between fresh and rehydrated rice for 6 items of appearance, flavor, taste, stickiness, hardness and overall evaluation. 4 and 10 kinds of free amino acids were detected from frseh and rehydrated rough rice and total free amino acid contents in fresh and rehydrated rough rice were 15.0 and $28.0 \mathrm{mg} 100 \mathrm{~g}^{-1}$, respectively.
\end{abstract}

\section{INTRODUCTION}

Rough rice is a hygroscopic, living and respiring biological material, which has an activity of respiratory metabolism to consume nourishment and oxygen, and generate carbon dioxide, water vapor and release energy in the form of heat (Daniels et al., 1998; Dillahunty et al., 2000). It absorbs and gives off moisture depending upon the rough rice moisture content, air relative humidity $(\mathrm{RH})$ and temperature of the surrounding atmosphere. As a living biological material, respiration rate of rough rice increased with rise in moisture content (Sahay and Gangopadhy, 1985). Especially after just harvest (moisture content of $24-26 \%$ wet basis), it has a high respiration rate and is very susceptible to attack by microorganisms, insects and pests. The heat evolved during the respiration process is retained in the grain and in the bulk because of the insulating effect of the rice husk. This heat increases the temperature of the grain resulting in increased mould

\footnotetext{
* The Commerce Department, Nagoya Gakuin University, Seto City 480-1298

** Laboratory of Postharvest Science, Division of Bioproduction System Science, Department of Bioproduction Environmental Science, Graduate School of Bioresource and Bioenvironmental Sciences, Kyushu University

*** Postdoctoral Fellow of Japan Society for the Promotion of Science, Laboratory of Postharvest Science, Division of Bioproduction System Science, Department of Bioproduction Environmental Science, Kyushu University

+ Corresponding author (E-mail:huxu@agr.kyushu-u.ac.jp)
} 
growth, fungi, insects and pests infection, which increase the quantitative loss and qualitative deterioration. Newly harvested rough rice with high moisture content must therefore be dried within 24 hours to about $14 \%$ for safe storage and milling or to at most $18 \%$ for temporary storage of up to two weeks in case the drying capacity will jeopardise the drying of the rest of the wet rough rice and thus get them spoiled (Cnossen and Siebenmorgen, 2000).

There are many theories as to what causes deterioration. Some of these include the effects of fungi or mold (Schroeder, 1963), high respiration rates (Schroeder, 1963), and elevated water activity, temperature and $\mathrm{CO}_{2}$ concentration (Bason et al., 1990). It has also been proposed that several of these factors interactively produce deterioration (Bason et al., 1990). In previous literatures, mold growth and heating occurred simultaneously in rough rice with higher moisture content (Milner, 1951; Phillips et al., 1988). The moisture content was one of the most important factors among environmental conditions for controlling the quality of rough rice (Hikida et al., 1996). Delayed, improper drying and absorbed the moisture from high $\mathrm{RH}$ air can cause heat burns or heat discoloration, deterioration. In some developing counitry, dried rough rice absorbed the moisture from high $\mathrm{RH}$ air and increased the moisture content in the rainy season, which resulted in large loss of rough rice. But there are little information about the effect of rehydration on respiration rate and quality of rough rice under high moisture content, high temperature and unsteady atmospheric conditions after just harvest. The objectives of this study were to investigate respiration rate of fresh and rehydrated rough rice at different moisture contents and storage temperatures in order to clarify the effect of rehydration on respiration and quality of rough rice. The quality evaluation of white rice milled from both rough rice was also determined.

\section{MATERIALS AND METHODS}

\section{Rough rice and storage conditions}

Rough rice (cv. Hinohikari) was harvested from Farm of Kyushu University in Fukuoka Preference, Japan. The moisture content was 23.7 and $22.2 \%$ wet base. They were transported to laboratory within $1 \mathrm{~h}$ and was stored at $5^{\circ} \mathrm{C}$ for use in experiment. Rehydrated rough rice was made by spraying water on the rough rice and covering it with film for 1 day to regulate the moisture content (24.6\%).

\section{Measurement of moisture content}

The sample of $10 \mathrm{~g}$ rough rice was taken and placed into the constant temperature dryer. It was dried for $24 \mathrm{~h}$ under $135^{\circ} \mathrm{C}$ and normal pressure. The moisture content was represented as wet base moisture content.

\section{Measurement of package atmosphere}

Samples of $300 \mathrm{~g}$ were placed in the pouches $(20 \mathrm{~cm} \times 15 \mathrm{~cm}$ in area, $0.0875 \mathrm{~mm}$ in thickness) and heat sealed. The film used for packaging was Krehalon film (Kureha Chemical Industry Co., Ltd. Tokyo, Japan), which is kind of high-barrier PVDC film that has no permeability. The pouches were stored at 20 and $30^{\circ} \mathrm{C}$, respectively.

The changes in gas concentration within the pouch were determined by gas chro- 
matography (GC-390, GL Sciences Inc, Tokyo Japan) equipped with thermal conductivity detector (TCD) and D2000 integrator (Hitachi, Ltd. Tokyo Japan) during storage. Helium was used as carrier gas and the flow rate was $30 \mathrm{ml} \mathrm{min}^{-1}$. Oven temperature was kept at $50^{\circ} \mathrm{C}$ whereas injector and column temperatures were 80 and $50^{\circ} \mathrm{C}$, respectively. The column was WG100 with molecular sieve $5 \mathrm{~A}$ and Porapak Q 80/100 mesh. The sampling intervals were $1-3 \mathrm{~h}$ according to changes in the gas concentration at different storage temperatures. Each time three replications were taken for the gas analysis and the average gas composition was recorded.

\section{Mathematical model for MAP}

To determine the respiration rate of rough rice under unsteady atmospheric conditions, pouch method based on the basic volume balance was used (Akimoto and Maezawa, 1997). The changes in the free volume of gas within package with time were shown in following equations.

$$
\begin{aligned}
& \frac{d V_{S}}{d t}=\frac{d V_{c}}{d t}+\frac{d V_{o}}{d t}+\frac{d V_{N}}{d t} \\
& \frac{d V_{C}}{d t}=\frac{A}{L} K_{C}\left(P_{C a}-P_{C}\right)+R_{c} W \\
& \frac{d V_{o}}{d t}=\frac{A}{L} K_{O}\left(P_{O a}-P_{o}\right)+R_{O} W \\
& \frac{d V_{N}}{d t}=\frac{A}{L} K_{N}\left(P_{N a}-P_{N}\right)
\end{aligned}
$$

where $V$ is the volume of gas in pouch (ml), $A$ is surface area of pouch $\left(\mathrm{m}^{2}\right), L$ is thickness of film (m), $K_{C}, K_{O}$ and $K_{N}$ are the permeability of film for $\mathrm{CO}_{2}, \mathrm{O}_{2}$ and $\mathrm{N}_{2}\left(\mathrm{ml} \mathrm{m} \mathrm{m} \mathrm{matm}^{-1}\right.$ $\left.\mathrm{h}^{-1}\right), R$ is respiration rate $\left(\mathrm{ml} \mathrm{kg}^{-1} \mathrm{~h}^{-1}\right), W$ is weight of product $(\mathrm{kg}), P_{C a}, P_{C a}$ and $P_{N a}$ are partial pressure of $\mathrm{CO}_{2}, \mathrm{O}_{2}$ and $\mathrm{N}_{2}$ outside pouch (atm), $P_{C}, P_{o}$ and $P_{N}$ are partial pressure of $\mathrm{CO}_{2}, \mathrm{O}_{2}, \mathrm{~N}_{2}$ inside pouch (atm).

\section{Sensory evaluations}

Palatability of rice was evaluated by ten people at laboratory according to evaluation standard of Japan Grain Inspection Association (JGIA). Evaluation was carried out on 6 items against those of standard rice: appearance, flavor, taste, stickiness, hardness and overall evaluation. They were scored on adding the following points based on 0 for the standard rice: slightly different \pm 1 ; a little different \pm 2 ; considerably different \pm 3 . Standard rice was Nipponbare from Konan, Shiga Prefecture, Class 1. The samples of white rice were milled from rough rice $(17.5 \%$ w.b.) and dehydrated rough rice (17.5\%w.b.) from rehydrated rough rice (24.6\%w.b.).

\section{Amino acid analysis}

The free amino acid was determined by extracting $10 \mathrm{~g}$ of grinded powder by grinder mixed with $75 \%$ ethanol, in a total volume of $100 \mathrm{ml}$. Extraction was taken $10 \mathrm{~h}$ from 
shaking at $50^{\circ} \mathrm{C}$. The homogenate was centrifuged at $12,000 \times \mathrm{g}$ for $30 \mathrm{~min}$. The supernatant was taken as sample to measure the free amino acid content by automatic amino acid analyzer (JLC-500/V, JEOL, Tokyo Japan).

\section{RESULTS AND DISCUSSION}

\section{Respiration rates of fresh and rehydrated rough rice}

Rough rice is a living and respiring biological material. Respiration is very low at moisture content of about 12-14\%. But it can absorb and give off moisture depending upon $\mathrm{RH}$ and temperature of the surrounding atmosphere due to its hygroscopicity. The experiment was carried out to compare the respiration of fresh rough rice to that of rehydrated rough rice.

Fig. 1 shows that changes in respiration rate, RQ and gas concentrations of fresh and rehydrated rough rice at $20^{\circ} \mathrm{C} . \mathrm{O}_{2}$ concentration decreased $90 \%$ from 19.1 to $2.0 \%, \mathrm{CO}_{2}$ concentration increased $88 \%$ from 1.9 to $16.0 \%$ during storage period (Fig. 1A). Under these conditions, $\mathrm{CO}_{2}$ production rate decreased $76 \%$ from 6.6 to $1.6 \mathrm{ml} \mathrm{kg}^{-1} \mathrm{~h}^{-1}, \mathrm{O}_{2}$ consumption rate showed similar trend of decrease to $\mathrm{CO}_{2}$ production rate over the initial $48 \mathrm{~h}$. And then $\mathrm{CO}_{2}$ and $\mathrm{O}_{2}$ levels in packages were 13.2 and $4.5 \%$, respectively. $\mathrm{O}_{2}$ consumption rate decreased quicker than $\mathrm{CO}_{2}$ production rate, indicating a shift to anaerobic respiration. This was confirmed by high $R Q$ value. RQ fluctuated around 0.8 and increased up to 2.3 after $60 \mathrm{~h}$. In Fig. $1 \mathrm{~B}, \mathrm{O}_{2}$ concentration was decreased $90 \%$ from 19.5 to $1.9 \%, \mathrm{CO}_{2}$ concentration was increased $95 \%$ from 1.0 to $18.8 \%$ during storage period. $\mathrm{CO}_{2}$ production rate decreased quickly from 29.2 to $19.3 \mathrm{ml} \mathrm{kg}^{-1} \mathrm{~h}^{-1}$ at initial $6 \mathrm{~h}$, and then it decreased slowly. $\mathrm{O}_{2}$ consumption rate showed similar trend of decrease to $\mathrm{CO}_{2}$ production rate during storage period. The RQ was fluctuated around 0.9 , and then increased after $30 \mathrm{~h}$.

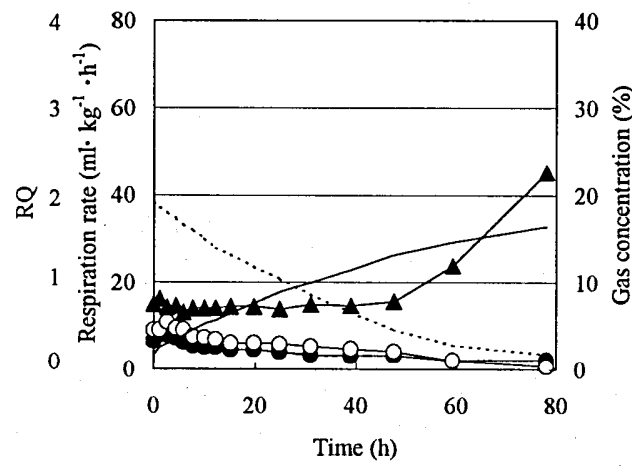

A: Fresh rough rice

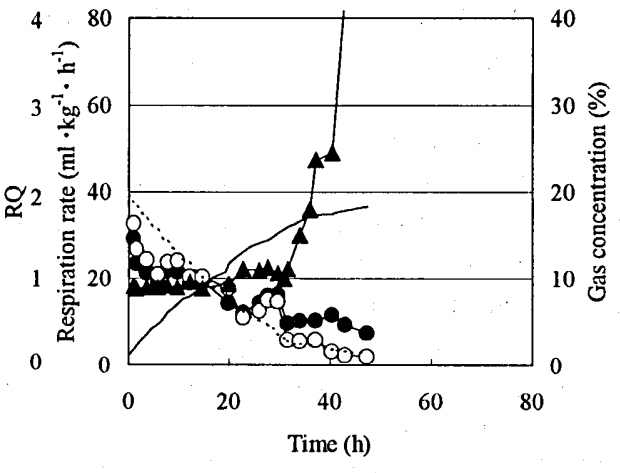

B: Rehydrated rough rice

Fig. 1. Changes in respiration rate, $R Q$ and gas concentration of fresh and rehydrated rough rice at $20^{\circ} \mathrm{C}$. (O) represents $\mathrm{CO}_{2}$ production rate, (O) $\mathrm{O}_{2}$ consumption rate, $(\square) \mathrm{RQ},(-) \mathrm{CO}_{2}$ concentration, (---) $\mathrm{O}_{2}$ concentration. 
The respiration rate, $\mathrm{RQ}$ and gas concentrations of fresh and rehydrated rough rice stored at $30^{\circ} \mathrm{C}$ can be seen in Fig. 2. $\mathrm{O}_{2}$ concentration decreased quickly $95 \%$ from 19.7 to $1.0 \%, \mathrm{CO}_{2}$ concentration increased $93 \%$ from 1.6 to $23.6 \%$ during storage period (Fig. 2A). $\mathrm{CO}_{2}$ production rate decreased $64 \%$ from 30.5 to $10.9 \mathrm{ml} \mathrm{kg}^{-1} \mathrm{~h}^{-1}$ over initial $12 \mathrm{~h}$ storage period, $\mathrm{O}_{2}$ consumption rate showed similar trend of decrease to $\mathrm{CO}_{2}$ production rate from initial $35.3 \mathrm{ml} \mathrm{kg}^{-1} \mathrm{~h}^{-1}$. The RQ fluctuated around 0.8 at initial $10 \mathrm{~h}$, and then it increased quickly. For rehydrated rough rice, $\mathrm{O}_{2}$ and $\mathrm{CO}_{2}$ concentrations were decreased quicker than that at $20^{\circ} \mathrm{C}$ during storage period (Fig. 2B). $\mathrm{CO}_{2}$ production and $\mathrm{O}_{2}$ consumption rates decreased quickly from 54.6 and $59.6 \mathrm{ml} \mathrm{kg}^{-1} \mathrm{~h}^{-1}$, respectively. RQ fluctuated around 0.9 , and then it increased after $18 \mathrm{~h}$.

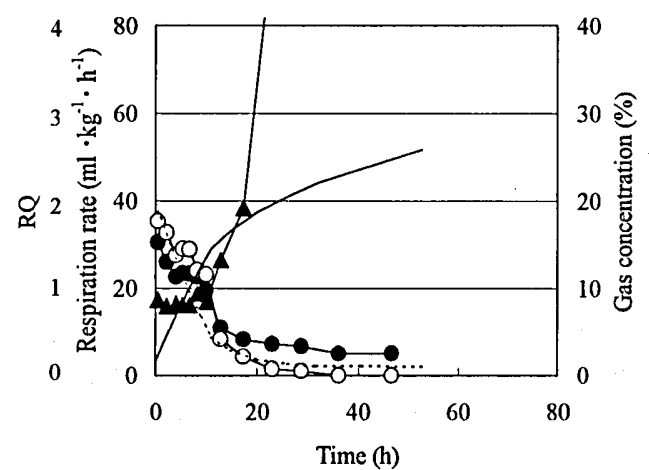

A: Fresh rough rice

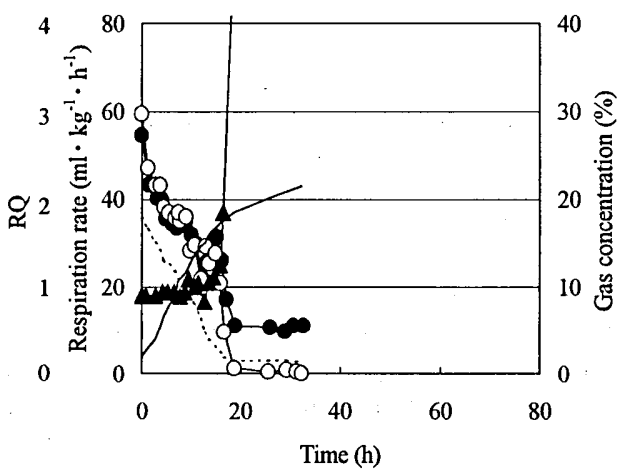

B: Rehydrated rough rice

Fig. 2. Changes in respiration rate, $R Q$ and gas concentration of fresh and rehydrated rough rice at $30^{\circ} \mathrm{C}$. (-) represents $\mathrm{CO}_{2}$ production rate, $(\mathrm{O}) \mathrm{O}_{2}$ consumption rate, $(\square) \mathrm{RQ},(-) \mathrm{CO}^{2}$ concentration, $(--) \mathrm{O}_{2}$ concentration.

Respiration was affected by the physiological state of rough rice as well as moisture content and temperature (Goto and Yamada, 1993). In this study, physiological metabolism activity of fresh rough rice, which was just harvested was lower than that of rehydrated rough rice. The paddy is harvested at mature stage and fresh rough rice is in certain state of dormancy. While rehydrated rough rice by absorbing water is on the contrary process from dormancy to activation. Therefore, although rehydrated rough rice had only $0.9 \%$ higher in moisture content $(24.6 \%)$ than that of fresh rough rice $(23.7 \%)$, rehydrated rough rice had higher physiological activity and showed relative high respiration rate. This suggests that rehydrated rough rice was used as experimental material that replaces fresh rough rice could not be ideal method.

\section{Relationship between $\mathrm{O}_{2}$ concentration and respiration rate of fresh and rehy- drated rough rice}

Fig. 3 shows changes in respiration rate and RQ with $\mathrm{O}_{2}$ concentration at $20^{\circ} \mathrm{C}$. Respiration rate of rehydrated rough rice was higher than that of fresh rough rice. The lower oxygen limit, the lowest $\mathrm{O}_{2}$ concentration sourrounding the product that dose not in 


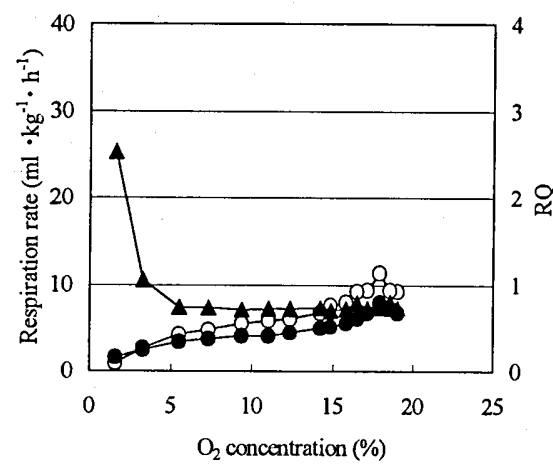

A: Fresh rough rice

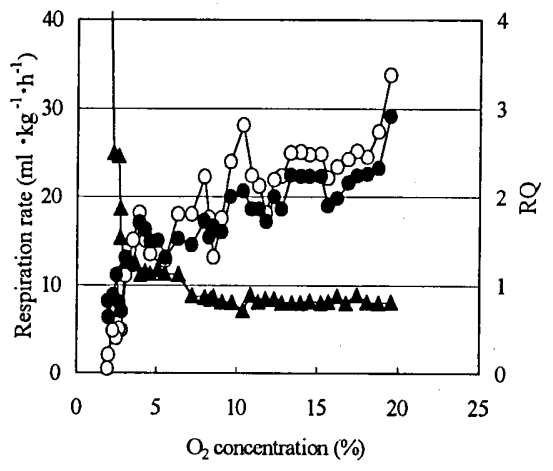

B: Rehydrated rough rice

Fig. 3. Relationship between $\mathrm{O}_{2}$ concentration and respiration rate, $\mathrm{RQ}$ of fresh rough rice at $20^{\circ} \mathrm{C}$. (O) represents $\mathrm{CO}_{2}$ production rate, (O) $\mathrm{O}_{2}$. consumption rate, $(\square) \mathrm{RQ}$.

duce fermentation, was $5.5 \%$ for fresh rough rice and $6.4 \%$ for rehydrated rough rice, respectively. It indicated that there was higher metabolic activity and lower oxygen limit in rehydrated rough rice. It was considered that although rehydration of dried rough rice is a process of absorbed water, it also activates the process of a certain physiological metabolism.

Fig. 4 shows changes in respiration rate and $\mathrm{RQ}$ with $\mathrm{O}_{2}$ concentration at $30^{\circ} \mathrm{C}$. It also indicated that rehydrated rough rice had higher respiration rate than that of fresh rough rice. For lower oxygen limit, it showed similar results, both of the lower oxygen limit of rehydrated and fresh rough rice was about $4.4 \%$. It has been reported that lower oxygen limit of fresh rough rice was about 5.5\% (Hu et al., 2001). In this experiment, the similar

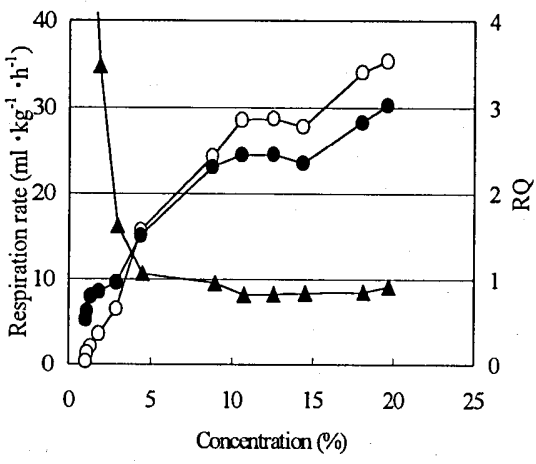

A: Fresh rough rice

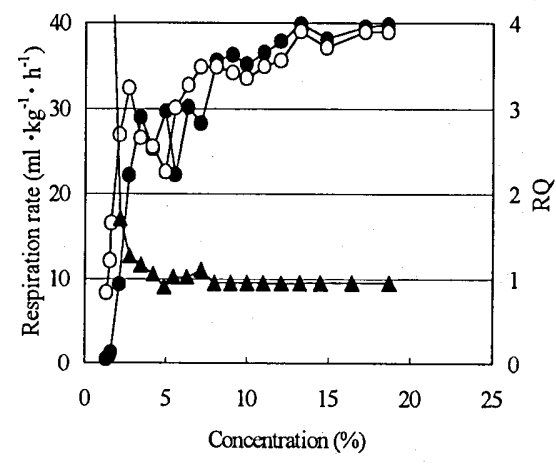

B: Rehydrated rough rice

Fig. 4. Relationship between $\mathrm{O}_{2}$ concentration and respiration rate, $\mathrm{RQ}$ of fresh rough rice at $30^{\circ} \mathrm{C}$. (O) represents $\mathrm{CO}_{2}$ production rate, (O) $\mathrm{O}_{2}$ consumption rate, ( $\square$ ) RQ. 
result of lower oxygen limit (4.4-6.4\%) was showed for both rehydrated and fresh rough rice.

\section{Effect of initial $\mathrm{O}_{2}$ concentration on respiration of fresh rough rice (22.2\%w.b.)}

Fig. 5 shows changes in respiration rate, $\mathrm{RQ}$ and gas concentration in the package at 20 and $30^{\circ} \mathrm{C}$. Respiration rate fluctuated $1.3-5.4 \mathrm{ml} \mathrm{kg}^{-1} \mathrm{~h}^{-1}$ for $\mathrm{CO}_{2}$ production rate, $1.2-2.6 \mathrm{ml} \mathrm{kg}^{-1} \mathrm{~h}^{-1}$ for $\mathrm{O}_{2}$ consumption rate (Fig. 5A). RQ fluctuated at large range of 0.7-3.0 from initial 1.1. At $30^{\circ} \mathrm{C}, \mathrm{CO}_{2}$ production rate decreased $80 \%$ from initial 9.2 to $1.8 \mathrm{ml} \mathrm{kg}^{-1} \mathrm{~h}^{-1} . \mathrm{O}_{2}$ consumption rate decreased $89 \%$ from initial $4.6-0.5 \mathrm{ml} \mathrm{kg}^{-1} \mathrm{~h}^{-1}$ (Fig. 5B). $\mathrm{RQ}$ decreased from initial 1.8 to 0.7 over initial $10 \mathrm{~h}$ storage period, and then increased quickly. These results indicated that respiration rate was markedly suppressed and RQ was changed irregularly at initial lower $\mathrm{O}_{2}$ level.

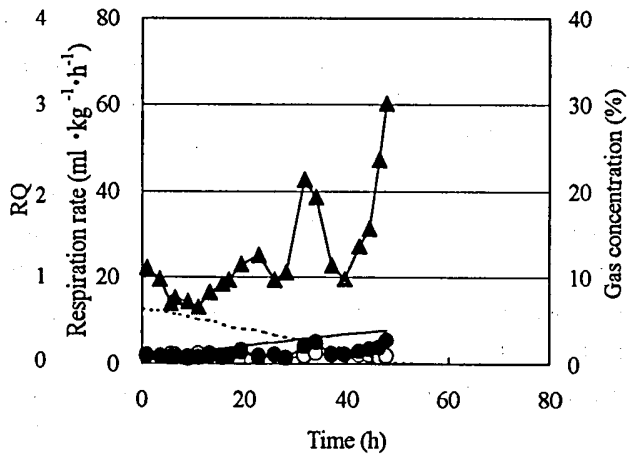

B: $20^{\circ} \mathrm{C}$

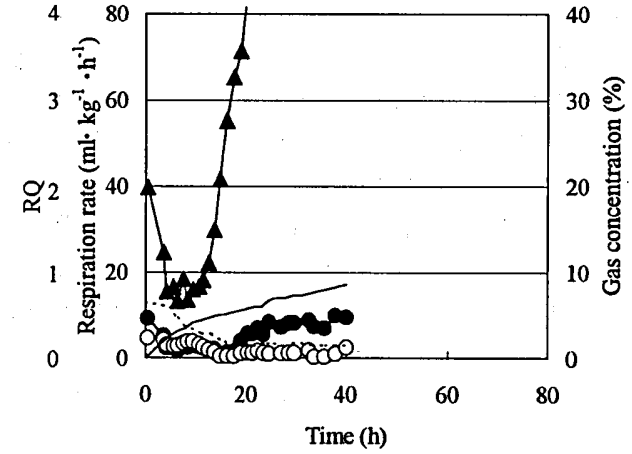

A: $30^{\circ} \mathrm{C}$

Fig. 5. Changes in respiration rate, $R Q$ and gas concentration of fresh and rehydrated rough rice under initial lower $\mathrm{O}_{2}$ conditions at different temperatures. (O) represents $\mathrm{CO}_{2}$ production rate, $(\mathrm{O})$ $\mathrm{O}_{2}$ consumption rate, $(\square) \mathrm{RQ},(-) \mathrm{CO}_{2}$ concentration, $(--) \mathrm{O}_{2}$ concentration.

\section{Evaluation of rice quality}

Palatability is commonly measured by sensory evaluation method based on the standard of JGIA. It involves many factors interacting with each other. Personal evaluation was carried out by actually eating rice to determine its taste. Taste of rice may vary depending on individuals' preferences and further on physiological and psychological conditions at the time of test.

Sensory evaluation of fresh and rehydrated rice and statistical analysis was showed in Table 1. Mean of overall evaluation, appearance and taste were higher for rehydrated rice than that of ordinary rice, while the values of stickiness and hardness were higher for ordinary rice than that of rehydrated rice, and mean of both flavor was the same. The statistical analysis of test of significance showed that there were no significant differences between ordinary and rehydrated rice for 6 items of appearance, flavor, taste, stickiness and overall evaluation. It was indicated that quality of white rice was not affected by rehydration of rough rice. 
Table 1. Sensory evaluation of rice milled from fresh and rehydrate rough rice and statistical analysis

\begin{tabular}{cccccc}
\hline Items & Fresh rice & $\begin{array}{c}\text { Rehydrated } \\
\text { Rice }\end{array}$ & $\begin{array}{c}\text { Standard deviation } \\
\text { of difference }\end{array}$ & $\begin{array}{c}\text { Standard error of } \\
\text { difference }\end{array}$ & $t_{0}$ \\
\hline Overall evaluation & 0.9 & 1.2 & 1.95 & 0.62 & $0.48^{-}$ \\
Appearance & 1.0 & 1.1 & 1.66 & 0.53 & $0.19^{-}$ \\
Flavor & 0.6 & 0.6 & 1.24 & 0.39 & $0.00^{-}$ \\
Taste & 0.9 & 1.2 & 1.95 & 0.62 & $0.48^{-}$ \\
Stickiness & 0.9 & 0.7 & 1.75 & 0.55 & $0.36^{-}$ \\
Hardness & -0.6 & -1.0 & 1.94 & 0.61 & $0.66^{-}$ \\
\hline
\end{tabular}

-Difference is not significant difference $(p<0.05)$.

The free amino acid contents in rough rice and rehydrated rough rice were showed in Table 2. Only 4 kinds of amino acid were detected from fresh rough rice, while 10 kinds of amino acid were inspected from rehydrated rough rice. Alanine and Glitamine con-

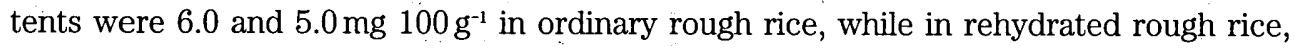

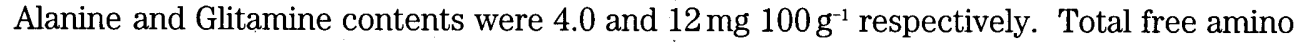

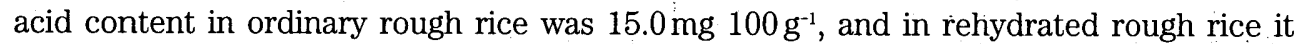

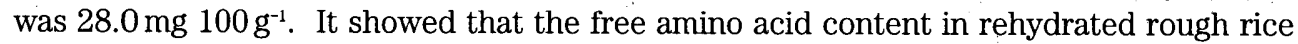
was 1.9 times as much as in ordinary rough rice. It has been reported that delicious rice could be gotten from higher level of some kinds of free amino acid content, while higher level of total free amino acid content in rice could not certainly be delicious (Fan et al., 2000). In this experiment, it showed that mean of overall evaluation, appearance and

Table 2. Free amino acid content in fresh and rehydrated rice (Limit of examination: $1 \mathrm{mg} \cdot 100 \mathrm{~g}^{-1}$ )

\begin{tabular}{ccc}
\hline $\begin{array}{c}\text { Kind of amino } \\
\text { acid }\end{array}$ & $\begin{array}{c}\text { Fresh rough rice } \\
\left(\mathrm{mg}^{\prime}\left(100 \mathrm{~g}^{-1}\right)\right.\end{array}$ & $\begin{array}{c}\text { Rehydrated rough rice } \\
\left(\mathrm{mg}^{\prime} \cdot 100 \mathrm{~g}^{-1}\right)\end{array}$ \\
\hline Alanine & 6.0 & 4.0 \\
Valine & $-*$ & 2.0 \\
Leucine & - & 1.0 \\
Isoleucine & - & - \\
Proline & - & 1.0 \\
Phenyalanine & - & - \\
Methionine & - & - \\
Glycine & - & 1.0 \\
Serine & 1.0 & 1.0 \\
Thronine & - & - \\
Tyrosine & - & - \\
Asparagine & 3.0 & 3.0 \\
Glutamine & 5.0 & 12.0 \\
Lysine & - & 1.0 \\
Arginine & - & 2.0 \\
Histidine & - & - \\
\hline
\end{tabular}

*Amino acid was not detected. 
taste were higher for rehydrated rice than that of ordinary rice, and mean of both flavor was the same. It was considered that components in rice, especially for level of free amino acid content, played inportant role in quality evaluation. The values of stickiness and hardness of rehydrated rice was decreased due to the change in starch nature by absorption of water.

\section{CONCLUSIONS}

Respiration rates of both fresh and rehydrated rough rice were greatly suppressed under conditions of increase in $\mathrm{CO}_{2}$ and decrease in $\mathrm{O}_{2}$ concentrations at 20 and $30^{\circ} \mathrm{C}$. But $\mathrm{O}_{2}$ and $\mathrm{CO}_{2}$ concentrations were decreased quicker for rehydrated rough rice due to higher respiration rate during storage period. RQ was fluctuated around 0.8-1.0 at over 4.4-6.4\% $\mathrm{O}_{2}$ concentration, and anaerobic respiration was occurred at less than this $\mathrm{O}_{2}$ level. For quality evaluation, statistical analysis of significance test of difference between the two population means showed that there were no significant differences in palatability between fresh and rehydrated rice for 6 items of appearance, flavor, taste, stickiness, hardness and overall evaluation. 4 and 10 kinds of free amino acids were detected from fresh and rehydrated rough rice, and total free amino acid contents in ordinary and rehydrated rough rice were 15.0 and $28.0 \mathrm{mg} 100 \mathrm{~g}^{-1}$, respectively.

\section{REFERENCES}

Akimoto, K. and S. Maezawa 1997 A new method for estimating respiration rate of fruits and vegetables in modified atmosphere packaging. J. of the J. Soc. Agri. Machineary, 59: 109-116

Bason, M. L., P. W. Gras, H. J. Bank and L. A. Esteves 1990 A quantitative study of the influence of temperature, water activity and storage atmosphere on the yellowing of paddy endosperm, J. Cereal Sci., 12: 193-201

Cnossen, A. G. and T. J. Siebenmorgen 2000 The glass transition temperature concept in rice drying and tempering: effect on milling quality, Transactions of the ASAE, 43: 1661-1667

Daniels, M. J., B. P. Marks, T. J. Siebenmorgen, R. W. Mcnew and J. F. Meullenet 1998 Effects of long-grain rough rice storage history on end-use quality, J. of Food Sci. 63: 832-835

Dillahunty, A. L., T. J. Siebenmorgen, R. W. Buescher, D. E. Smith and A. Mauromoustakos 2000 Effect of moisture content and temperature on respiration rate of rice, Cereal Chem. 77: 541-543

Fan, J., T. J. Siebenmorgen and W. Yang 2000 A study of head rice yield reduction of long-and medium-grain rice varieties in relation to various harvest and drying conditions, Transactions of the ASAE, 43: 1709-1714

Goto, K., Y. Miwa and K. Yamada 1993 Study on respiration characteristics of grain (part I)-simplified measuring procedure and general characteristics-, J. the Japanese Soc. Agri. Machinery, 55: 51-57

Hikida, Y., D. H. Han and T. Abe 1996 Studies on the respiration rate of rough rice, J. the Japanese Soc. Agri. Machinery, 58: 25-30

Hu, W., E. Yasunaga, T. Uchino and Y. Hori 2001 Respiratory characteristic of rough rice under unsteady atmospheric condition, Sci. Bull. Fac. Agr., Kyushu Uni., 56: 53-58, 2001

Milner, M. 1951 Biological factors in damp grain deterioration, Food Technol., 5: 25-30

Phillips, S., S. Widjaja A. Wallbridge and R. Cook 1988 Rice yellowing during post-harvest drying by aeration and during storage, $J$. Stored Prod. Res., 24: 173-181

Sahay, M. N. and S. Gangopadhyay 1985 Effect of wet harvesting on biodeterioation of rice, Cereal Chem., 62: 804-808

Schroeder, H. W. 1963 The relationship between storage molds and damage in high-moisture rice in aerated storage, Phytopathology, 53: 804-808 